\title{
$\mathrm{Ca}_{1-\mathrm{x}} \mathrm{Sr}_{\mathrm{x}} \mathrm{Al}_{2} \mathrm{O}_{4}: \mathrm{Eu}^{2+}$ 형광체의 상전이 및 발광특성에 관한 연구
}

\author{
박윤진 · 송현돈* · 정상현** · 이지희 · 황민하 · 김영진 ${ }^{\dagger}$ \\ 경기대학교 재료공학과 \\ *(주)에피플러스, **(주)대주 전자재료
}

\section{Phase Transformation and Luminescent Properties of $\mathrm{Ca}_{1-\mathrm{x}} \mathrm{Sr}_{\mathrm{x}} \mathrm{Al}_{2} \mathrm{O}_{4}: \mathrm{Eu}^{2+}$ Phosphors}

\author{
Yun Jin Park, Hyundon Song*, Sang Hyun Jung**, Jee Hee Lee, Min Ha Hwang and Young Jin Kim* \\ Dept. of Materials Science and Engineering, Kyonggi University \\ *EPIPLUS Inc, Eyon-Hansan Industrial Park, Pyongtaek, Korea \\ **DAEJOO ELECTRONIC MATERIALS Co., Shiwha Ind. Estate IRA-110, Shiheung, Korea
}

(2007년 11월 19일 접수 : 2007년 12월 10일 채택)

\begin{abstract}
The phase transformations and luminescent properties of Eu-doped $\mathrm{Ca}_{1-\mathrm{x}} \mathrm{Sr}_{\mathrm{X}} \mathrm{Al}_{2} \mathrm{O}_{4}$ phosphors were investigated. $\mathrm{Ca}_{1-\mathrm{x}} \mathrm{Sr}_{\mathrm{x}} \mathrm{Al}_{2} \mathrm{O}_{4}: \mathrm{Eu}^{2+}$ phosphors were synthesized by a solid-state reaction with a flux, $\mathrm{H}_{3} \mathrm{BO}_{3}$. A phase transformation from monoclinic $\mathrm{CaAl}_{2} \mathrm{O}_{4}$ to monoclinic $\mathrm{SrAl}_{2} \mathrm{O}_{4}$ was observed as the $\mathrm{x}$ values increased. A high-temperature hexagonal phase of $\mathrm{SrAl}_{2} \mathrm{O}_{4}$ was formed during this transformation as an intermediate phase under an $\mathrm{H}_{2}$ atmosphere due to oxygen vacancies; this did not occur in an air atmosphere. Accordingly, the emission spectra shifted from a blue region to a green region as $\mathrm{x}$ increased.
\end{abstract}

Key words strontium-aluminates, calcium-aluminates, luminescence, europium, phase transformation.

\section{1. 서 론}

반도체 조명으로서 $\operatorname{LED}($ Light emitting diode)는 에너 지를 절약하고 환경오염을 감소시키는데 도움을 주는 것 으로 알려져 있다. 현재 nUV(near ultraviolet)로 여기시 키는 백색 $\mathrm{LED}$ 의 개발이 중요한 논점이 되고 있으며, 이에 따라서 적합한 형광체의 개발도 많은 연구가 진행 되고 있다.

$\mathrm{Eu}^{2+}$ 가 도핑 된 알칼리 토류 알루미네이트(alkaline-earth aluminates) 형광체는 높은 발광강도, 긴 발광시간, 우수 한 발광색 그리고 화학적 안정성이 뛰어나기 때문에 백 색 $\mathrm{LED}$ 용 발광재료의 모재로서 널리 연구되어 왔다. ${ }^{1-3)}$ 특히 $\mathrm{CaAl}_{2} \mathrm{O}_{4}, \mathrm{SrAl}_{2} \mathrm{O}_{4}$ 그리고 $\mathrm{Sr}_{4} \mathrm{Al}_{14} \mathrm{O}_{25}$ 화합물이 가장 많이 이용되고 있으며, 각각 청색/녹색 영역에서 강한 발 광을 보인다. ${ }^{4-6} \mathrm{Sr}_{4} \mathrm{Al}_{14} \mathrm{O}_{25}$ : $\mathrm{Eu}, \mathrm{Dy}$ 형광체는 잔광시간이 길 게 나타나는 축광체로 널리 알려져 있다. 이는 여기광이 제거된 후에도 Dy에 의해서 생성된 홀의 trap 레벨에서 $\mathrm{Eu}^{1+}$ 의 전자와 재결합에 의한 것이다. ${ }^{7)}$

$\mathrm{CaAl}_{2} \mathrm{O}_{4}$ 와 $\mathrm{SrAl}_{2} \mathrm{O}_{4}$ 는 트리디마이트(tridymite) 타입의 단사정 (momoclinic) 구조를 가지며 각각 $\mathrm{P} 2_{1} / \mathrm{n}$ 과 $\mathrm{P} 2_{1}$ 의

Corresponding author

E-Mail : yjkim@kyonggi.ac.kr (Y. J. Kim)
공간군에 속한다. ${ }^{2,6)} \mathrm{SrAl}_{2} \mathrm{O}_{4}$ 의 경우 $650^{\circ} \mathrm{C}$ 이하에서는 단사정으로 존재하지만 $650^{\circ} \mathrm{C}$ 이상에서는 상전이가 발생 하여 육방정 (hexagonal)으로 존재한다. 육방정 $\mathrm{SrAl}_{2} \mathrm{O}_{4}$ 는 단사정 $\mathrm{SrAl}_{2} \mathrm{O}_{4}$ 보다 더 높은 발광 효율을 갖고 있 으나 불안정 하여 상온에서 존재하는 것이 어렵다고 보 고되어 있다.-9)

최근 구조적 특성과 발광특성에 대한 관심이 증가하고 있는 $\mathrm{CaAl}_{2} \mathrm{O}_{4}-\mathrm{SrAl}_{2} \mathrm{O}_{4}$ 시스템 형광체는 $\mathrm{Sr}$ 원자가 $\mathrm{Ca}$ 자 리를 치환함으로써 전자 전이가 발생하며, 그로 인해 길 게 지속되는 잔광 특성을 갖는다.

보고된 연구에 의하면 $\mathrm{Ca}_{1-\mathrm{x}} \mathrm{Sr}_{\mathrm{x}} \mathrm{Al}_{2} \mathrm{O}_{4}: \mathrm{Eu}^{2+}$ 에서 양이온 치환 비율에 따라서 합성상과 발광특성이 변하는 것으로 알려져 있다.1,10-11) 그러나 결정상 전이와 발광특성 간의 관계에 대하여 자세히 언급되고 있지 못하며, 양이온 치 환 비율에 따라서 발광파장의 이동에 대하여 각기 다른 결과를 보고하고 있다. Chen et al.은 $\mathrm{Sr}$ 의 첨가에 따라 청색이동 (blue shift)이 발생한다고 하였으며, 이러한 현 상을 $\mathrm{Sr}$ 의 농도 증가에 따른 결정장 세기의 감소로 설명 하였다. 반면에 Ju et al.는 $\mathrm{Sr}$ 첨가에 따라 적색이동(red shift)이 일어난다고 상반된 결과가 보고되고 있다. 따라서 본 실험에서는 이에 대한 정확한 메커니즘을 규명하기 위 하여 양이온 치환 비율에 따른 상전이 특성을 분석하고 
이에 따른 발광특성 변화에 대한 연구를 수행하였다.

\section{2. 실험 방법}

본 실험에서는 고상 반응에 의한 분말 합성을 시도하 였다. 원료 물질로는 $\mathrm{Al}_{2} \mathrm{O}_{3}$ (Aldrich, $99.99 \%$ )와 $\mathrm{CaCO}_{3}$ (High Purity Chemical, 99.99\%) 그리고 $\mathrm{SrCO}_{3}$ (Aldrich, $99.9 \%$ )를 사용하였으며, $\mathrm{CaCO}_{3}$ 와 $\mathrm{SrCO}_{3}$ 는 $1100^{\circ} \mathrm{C}$ 에서 하소하여 각각 $\mathrm{CaO}$ 와 $\mathrm{SrO}$ 로 제조하여 사용하였다. 도 펀트로는 $\mathrm{Eu}_{2} \mathrm{O}_{3}$ (Aldrich, 99.99\%)를 사용하였으며 1 $\mathrm{mol} \%$ 를 첨가하였다. 알루미네이트계 화합물은 합성온도 가 높기 때문에 융제를 첨가하여 합성온도를 낮추고자 하 였으며, 융제로는 $\mathrm{H}_{3} \mathrm{BO}_{3}$ 를 선택하여 사용하였다. $\mathrm{H}_{3} \mathrm{BO}_{3}$ 는 합성온도에서 $\mathrm{H}_{2} \mathrm{O}$ 가 증발되고 액상의 $\mathrm{B}_{2} \mathrm{O}_{3}$ 만이 $\mathrm{CaO}$ / $\mathrm{SrO}$ 와 $\mathrm{Al}_{2} \mathrm{O}_{3}$ 입자 사이에 존재함으로써 고상입자를 재 정렬 시켜 높은 밀도와 낮은 기공성을 갖게 한다. 또한 반응을 촉진시키고 모재의 표면에 활성제가 균일하게 분 포될 수 있도록 하여 발광특성을 향상시키는 역할을 하 는 것으로 보고되어 있다. ${ }^{12-13)}$ 혼합된 분말 시료는 24시 간 동안 건식 볼밀 한 후, $1300^{\circ} \mathrm{C}$ 에서 3 시간 동안 열처 리 하였다. 열처리는 각각 산화분위기와 $5 \% \mathrm{H}_{2}+95 \% \mathrm{~N}_{2}$ 가스를 $50 \mathrm{cc} / \mathrm{min}$ 흘려주는 환원분위기에서 하였다. 냉각 속도는 열처리온도에서 $600^{\circ} \mathrm{C}$ 까지는 $1.67^{\circ} \mathrm{C} / \mathrm{min}$, 상온까 지는 $2.4^{\circ} \mathrm{C} / \mathrm{min}$ 의 속도로 냉각하였다.

합성된 형광체의 결정상은 $\mathrm{XRD}(\mathrm{X}$-ray diffractometer, PHILIPS X'PERT)를 이용하여 관찰하였다. X-선의 파장 은 $1.5406 \AA(\mathrm{Cuk} \alpha)$ 이었으며, 주사각도는 $20-70^{\circ}$ 이고, 주 사속도는 $0.14 \% \mathrm{sec}$ 이다. 발광특성은 $\mathrm{Xe}$ 램프를 여기 광 원으로 사용하는 PL(Photoluminescence, PSI Darsa-5000) 시스템으로 측정하였다.

\section{3. 결과 및 고찰}

$\mathrm{Ca}_{1-\mathrm{x}} \mathrm{Sr}_{\mathrm{x}} \mathrm{Al}_{2} \mathrm{O}_{4}: \mathrm{Eu}^{2+}(2 \mathrm{~mol} \%)$ 에서 $\mathrm{x}$ 에 따른 $\mathrm{XRD}$ 패턴 의 변화를 Fig. 1 에 나타내었다. $\mathrm{x}=0$ 에서 단사정 $\mathrm{CaAl}_{2} \mathrm{O}_{4}$ (M-CA) 단일상이 합성되었으며, $\mathrm{x}$ 의 증가에 따라서 $\mathrm{M}$ $\mathrm{CA}$ 의 주피크인 $30.1^{\circ}$ 에서의 (220)피크가 연속적으로 낮 은 각도로 이동하는 것을 볼 수 있었다. 이는 $\mathrm{Ca}_{1-x} \mathrm{Sr}_{x} \mathrm{Al}_{2} \mathrm{O}_{4}$ : $\mathrm{Eu}^{2+}$ 에서 $\mathrm{Ca}^{2+}$ 자리에 치환되는 $\mathrm{Sr}^{2+}$ 의 크기 $(1.31 \AA)$ 가 $\mathrm{Ca}^{2+}$ 의 크기 (1.18)보다 크기 때문이다. ${ }^{11)} \mathrm{x}=0.81$ 이 되면 서 육방정 $\mathrm{SrAl}_{2} \mathrm{O}_{4}(\mathrm{H}-\mathrm{SA})$ 이 주도하는 결정상으로 상전이가 일어나며, $x=1$ 이 되면서 다시 단사정 $\mathrm{SrAl}_{2} \mathrm{O}_{4}(\mathrm{M}-\mathrm{SA})$ 단일상으로 상전이가 일어나는 것을 알 수 있었다. 한편 매우 소량의 $\mathrm{Sr}_{4} \mathrm{Al}_{14} \mathrm{O}_{25}$ 가 이차상으로 관찰 되었으나 본 실험의 결과에는 거의 영향을 주지 못하고 있었다.

JCPDS 데이터로부터 볼 수 있듯이 M-CA와 H-SA는 거의 같은 XRD 패턴을 보이고 있으므로 이들 두 상을

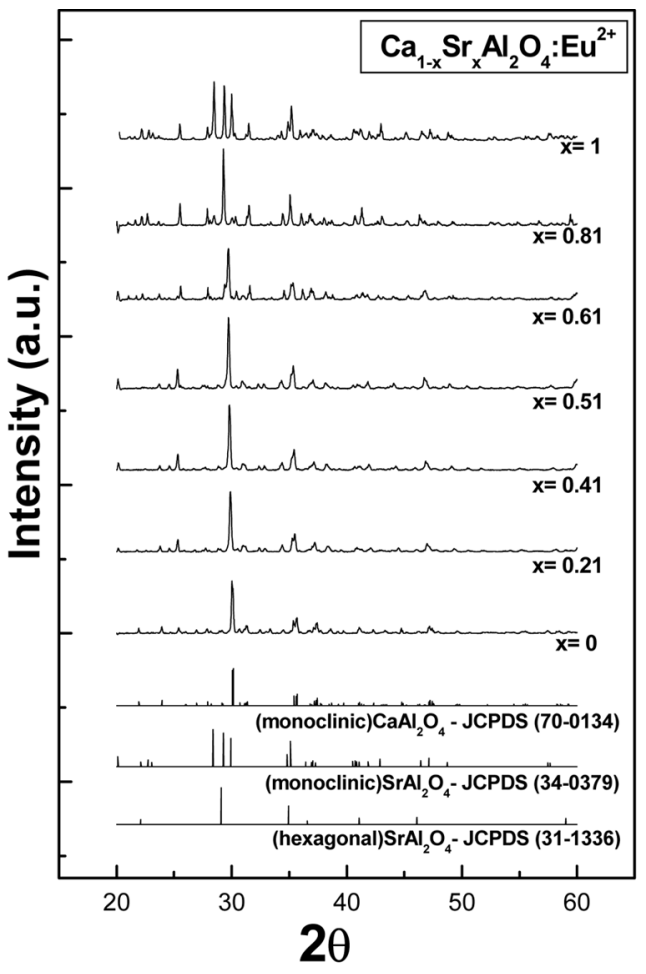

Fig. 1. XRD patterns of $\mathrm{Ca}_{1-\mathrm{x}} \mathrm{Sr}_{\mathrm{X}} \mathrm{Al}_{2} \mathrm{O}_{4}: \mathrm{Eu}^{2+}$ powders fired at $\mathrm{H}_{2}$ atmosphere as a function of $\mathrm{x}$.

정확히 구분할 수 없었다. 따라서 XRD 방법으로는 $\mathrm{x}$ $=0.21 \sim 0.81$ 까지의 구간에서 $\mathrm{M}-\mathrm{CA}$ 와 $\mathrm{H}-\mathrm{SA}$ 에 대한 정확 한 분석은 할 수 없었으나, 주도적인 상이 어느 것인가 는 판단할 수 있었다.

Prodjosantoso and Kennedy에 의하면 Rietvald 법으로 분석한 결과 $\mathrm{x}$ 에 따라서 한 개의 상에서부터 세 개의 상 (M-CA, H-SA, M-SA)이 모두 존재할 수도 있다고 보고 하고 있다. ${ }^{14)}$ 즉, $\mathrm{x}=0$ 에서 $\mathrm{M}-\mathrm{CA}$ 단일상이 존재하다가 $\mathrm{x}$ 의 증가에 따라서 $\mathrm{M}-\mathrm{CA}, \mathrm{H}-\mathrm{SA}, \mathrm{M}-\mathrm{SA}$ 의 3 개 상이 공 존하고 그 후 $\mathrm{H}-\mathrm{SA}$ 와 $\mathrm{M}-\mathrm{SA}$ 가 공존하다가 $\mathrm{x}=1$ 이 되 면서 M-SA 단일상이 합성된다고 보고하고 있다.

앞서 기술한 바와 같이 XRD 방법으로는 몇 개의 상 이 공존하는 지는 정확히 알 수 없었으나, Fig. 2의 PL 스펙트럼으로부터 주도하는 상이 무엇인지는 판단할 수 있었다. 또한 이를 Fig. 3 과 같이 $x$ 에 따른 발광피크 위 치변화로 나타내 보았다.

$\mathrm{PL}$ 스펙트럼에서 볼 수 있듯이 (I) 영역인 $\mathrm{x}=0 \sim 0.41$ 까지는 $450 \mathrm{~nm}$ 근처에서 청색 발광을 하고 있다. $\mathrm{Eu}^{2+}$ 가 치환된 $\mathrm{M}-\mathrm{CA}$ 의 경우가 청색 발광을 하고 $\mathrm{SA}$ 의 경 우는 녹색 발광을 하므로 청색발광을 하는 $\mathrm{x}=0.21$ 0.41 에서는 M-CA상이 주도하고 있음을 알 수 있었다. 한 편 $\mathrm{x}=0$ 인 경우의 $\mathrm{M}-\mathrm{CA}$ 단일상의 $\mathrm{PL}$ 피크보다는 $\mathrm{x}=$ $0.21 \sim 0.41$ 인 경우 적색이동이 관찰되고 있다. 이는 $\mathrm{Ca}^{2+}$ 와 이온 크기가 다른 $\mathrm{Sr}^{2+}$ 의 치환에 따라서 $\mathrm{Eu}^{2+}$ 주위 


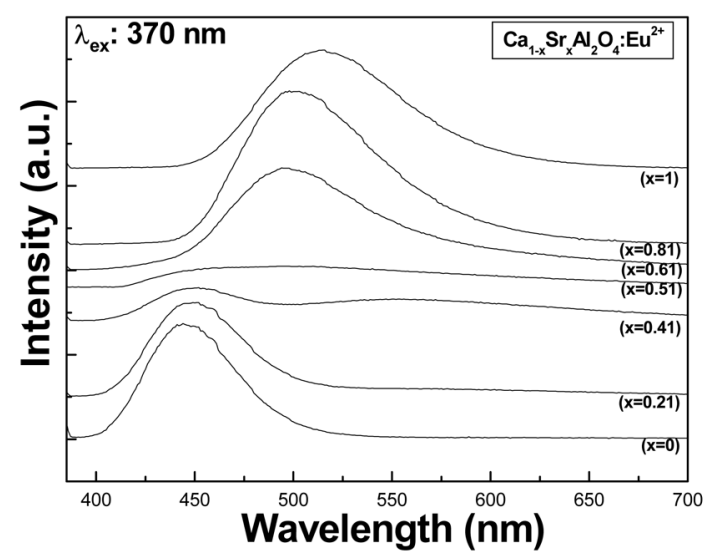

Fig. 2. $\mathrm{PL}$ spectra of $\mathrm{Ca}_{1-\mathrm{x}} \mathrm{Sr}_{\mathrm{x}} \mathrm{Al}_{2} \mathrm{O}_{4}: \mathrm{Eu}^{2+}$ powders fired at $\mathrm{H}_{2}$ atmosphere as a function of $\mathrm{x}$.

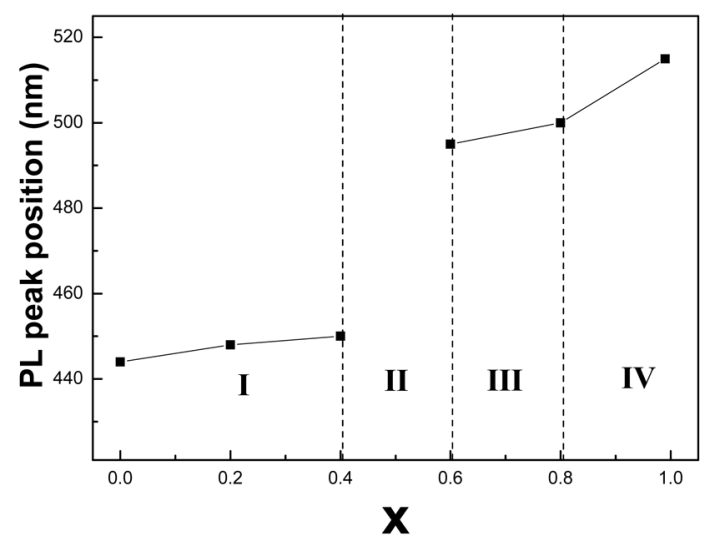

Fig. 3. $\mathrm{PL}$ peak positions of $\mathrm{Ca}_{1-\mathrm{x}} \mathrm{Sr}_{\mathrm{x}} \mathrm{Al}_{2} \mathrm{O}_{4}: \mathrm{Eu}^{2+}$ powders fired at $\mathrm{H}_{2}$ atmosphere as a function of $\mathrm{x}$.

의 결정장에 변화가 생겼기 때문이다. 발광은 $\mathrm{Eu}^{2+}$ 이온 의 $4 \mathrm{f}^{7}\left({ }^{8} \mathrm{~S}_{7 / 2}\right)$ 기저상태와 $4 \mathrm{f}^{6} 5 \mathrm{~d}^{1}$ 의 여기 상태 사이에서 에너지 전이에 의해 일어난다. ${ }^{5,12}$ 결정 격자와 강하게 결 합하고 있는 $\mathrm{Eu}^{2+}$ 이온의 $5 \mathrm{~d}$ 전자는 주위 격자의 변형에 매우 민감하기 때문에 모재의 결정구조에 따라 치환된 $\mathrm{Eu}^{2+}$ 의 결정장이 변하게 되며, 이로 인해 $4 \mathrm{f}$ 와 $5 \mathrm{~d}$ mixed state가 분리되어 발광특성의 차이를 가져온다고 생각된다.

$\mathrm{x}=0.51$ 이 되면서(II영역) PL 스펙트럼의 피크가 거의 평탄해지는 것으로 보아 M-CA와 H-SA가 거의 같은 양 으로 공존하여 상호 발광 간섭에 의해서 특정 파장에서 피크가 보이지 않고 있음을 알 수 있었다. 보고된 바에 의하면 $\mathrm{Ca}_{1-\mathrm{x}} \mathrm{Sr}_{\mathrm{x}} \mathrm{Al}_{2} \mathrm{O}_{4}: \mathrm{Eu}^{2+}$ 형광체내에서 활성제인 $\mathrm{Eu}^{2+}$ 가 $\mathrm{Ca}_{0.5} \mathrm{Sr}_{0.5} \mathrm{Al}_{2} \mathrm{O}_{4}$ 격자의 $\mathrm{Ca}^{2+} / \mathrm{Sr}^{2+}$ 자리를 무질서하게 치환 하면 결정장이 갈라지게 되고 갈라진 결정장의 상호작용 에 의해 $5 \mathrm{~d}$ 레벨에 변화가 발생하여 발광파장이 완만하 게 나타난다고 보고하고 있다. ${ }^{1,11)}$ (III)영역인 $\mathrm{x}=0.61$ 0.81 이 되면서 $500 \mathrm{~nm}$ 근처에서의 녹색 발광으로 급격 히 변하고 있다. 이로 보아 청색 발광을 하는 M-CA상
보다는 녹색 발광을 하는 $\mathrm{H}-\mathrm{SA}$ 이 주도하는 결정상으로 전이가 일어났다고 볼 수 있다. 즉, 이 영역에서는 $\mathrm{Ca}$ 자리를 $\mathrm{Sr}$ 이 치환한 것이 아니라, 반대로 $\mathrm{Sr}$ 알루미네이 트를 모재로 $\mathrm{Ca}$ 가 $\mathrm{Sr}$ 자리를 치환했다고 봐야한다. (IV) 영역의 $\mathrm{x}=1$ 이 되면서 발광피크는 적색이동이 일어나고 $\mathrm{M}-\mathrm{SA}$ 의 단일상이 관찰되고 있다. 그러나 H-SA 상에서 M-SA가 되면서 발광 강도는 약간 감소하고 있었다. $\mathrm{H}-$ $\mathrm{SA}$ 에서 M-SA로의 상전이에 대한 설명은 뒤에 기술하 고 있다.

단일상이라는 가정하에서는 양이온 치환의 관점에서 보 면 $\mathrm{Sr}^{2+}$ 의 이온반경이 $\mathrm{Ca}^{2+}$ 보다 크기 때문에 결정장의 세기가 약해지므로 $\mathrm{x}=0.61 \sim 1$ 의 영역에서 $\mathrm{Sr}^{2+}$ 의 증가에 따라 청색이동이 일어나야 한다. 하지만 앞서 기술한 바 와 같이 본 실험에서는 적색이동이 발생하였다. 그 이유 는 이 구간에서 주도상은 $\mathrm{SA}$ 이지만 소량의 $\mathrm{CA}$ 상도 공 존하고 있기 때문이다. 즉, 서로 다른 크기의 양이온 치 환에 따른 결정장 변화보다는 두 상의 공존에 의해 발 생된 내부 응력의 영향을 더 크게 받았기 때문에 적색 이동이 일어난 것이다.

$\mathrm{Sr}$ 의 첨가량에 따른 $\mathrm{Ca}_{1-\mathrm{x}} \mathrm{Sr}_{\mathrm{x}} \mathrm{Al}_{2} \mathrm{O}_{4}: \mathrm{Eu}^{2+}$ 의 여기 스펙트 럼은 Fig. 4과 같으며, $320 \mathrm{~nm} 380 \mathrm{~nm}$ 의 파장에서 광범 위한 흡수가 일어나고 있는 것을 볼 수 있다. $\mathrm{x}=0$ 인 경 우 $330 \mathrm{~nm}$ 부근에서 가장 강한 흡수를 보였으나, $\mathrm{Sr}$ 의 양 이 증가함에 따라 $370 \mathrm{~nm}$ 부근의 흡수 세기가 점점 증

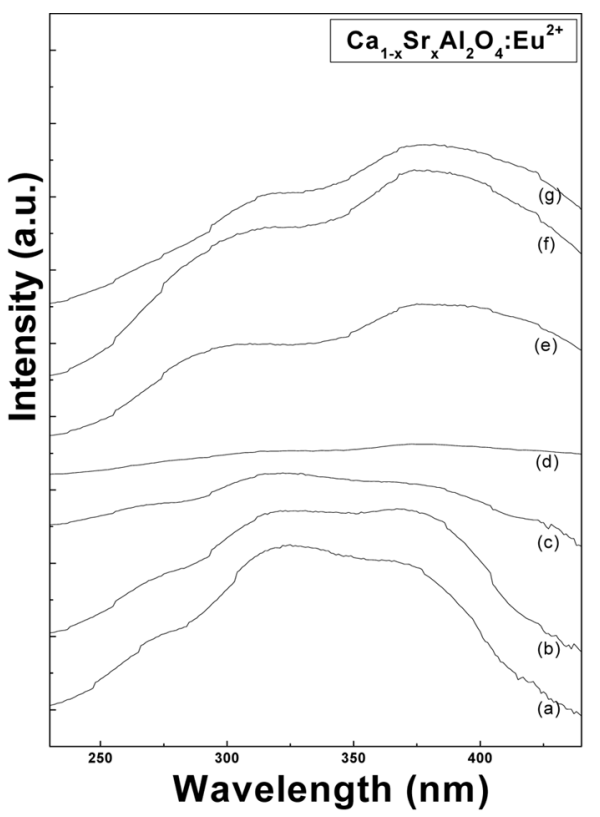

Fig. 4. $\mathrm{PL}$ excitation spectra of $\mathrm{Ca}_{1-\mathrm{x}} \mathrm{Sr}_{\mathrm{x}} \mathrm{Al}_{2} \mathrm{O}_{4}: \mathrm{Eu}^{2+}$ phosphors fired at $\mathrm{H}_{2}$ atmosphere as a function of $\mathrm{x}$. (a) $\lambda_{\mathrm{em}}: 440 \mathrm{~nm}$ $(\mathrm{x}=0)$, (b) $\lambda_{\mathrm{em}}: 450 \mathrm{~nm}(\mathrm{x}=0.21)$, (c) $\lambda_{\mathrm{em}}: 450 \mathrm{~nm}$ $(\mathrm{x}=0.41)$, (d) $\lambda_{\mathrm{em}}: 490 \mathrm{~nm}(\mathrm{x}=0.51)$, (e) $\lambda_{\mathrm{em}}: 490 \mathrm{~nm}$ $(\mathrm{x}=0.61),(\mathrm{f}) \lambda_{\mathrm{em}}: 500 \mathrm{~nm}(\mathrm{x}=0.81)$ and $(\mathrm{g}) \lambda_{\mathrm{em}}: 500 \mathrm{~nm}$ $(\mathrm{x}=1)$ 


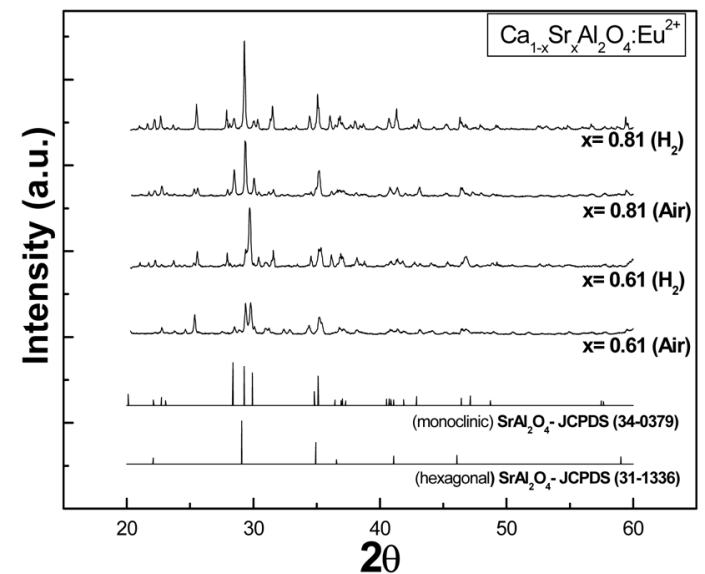

Fig. 5. XRD patterns of $\mathrm{Ca}_{1-\mathrm{x}} \mathrm{Sr}_{\mathrm{x}} \mathrm{Al}_{2} \mathrm{O}_{4}: \mathrm{Eu}^{2+}(\mathrm{x}=0.61 \sim 0.81)$ phosphors fired at $\mathrm{H}_{2}$ and air atmospheres, respectively.

가하고 있으며, $\mathrm{x}=0.6$ 이상이 되면 $370 \mathrm{~nm}$ 부근에서 가 장 강한 흡수를 하는 것을 알 수 있다. $370 \mathrm{~nm}$ 는 $\mathrm{SA}$ 의 주 여기 파장으로 ${ }^{15)} 0.61 \mathrm{~mol}$ 이상의 $\mathrm{Sr}$ 이 첨가됨에 따 라 $\mathrm{CA}$ 에서 $\mathrm{SA}$ 로 상전이가 발생하여 에너지를 흡수하는 모재의 변화에 의해 여기 파장의 위치 및 모양이 변하 게 된 것이다.

앞서 기술된 바와 같이 영역 (IV)에서는 H-SA가 고 온 안정상임에도 불구하고 주도적인 상으로 나타나고 있 다. 저온 안정상인 $\mathrm{M}-\mathrm{SA}$ 와 $\mathrm{H}-\mathrm{SA}$ 사이의 전이온도는 $650^{\circ} \mathrm{C}$ 로서 상온에서는 $\mathrm{H}-\mathrm{SA}$ 가 얻어지기 매우 힘들다. 이 미 보고된 바에 의하면 H-SA상을 얻기 위하여 일반적 으로 급속 냉각 방법을 이용하고 있다. ${ }^{16-17)}$

Shi et al.에 의하면 상온에서의 H-SA의 합성에는 산 소 공공이 기여할 수 있다고 보고하고 있다. ${ }^{8)}$ 따라서 본 실험에서는 $\mathrm{Ca}_{1-\mathrm{x}} \mathrm{Sr}_{\mathrm{x}} \mathrm{Al}_{2} \mathrm{O}_{4}: \mathrm{Eu}^{2+}(\mathrm{x}=0.61 \sim 0.81)$ 를 환원분 위기와 산화분위기에서 각각 합성하였으며, 그 결과는 Fig. 5 의 $\mathrm{XRD}$ 와 같다. 그림에서 볼 수 있듯이 환원 분위기 에서 합성한 시편의 경우 $\mathrm{H}-\mathrm{SA}$ 가 주도적인 상을 보이 고 있었으나, 산화 분위기에서 합성한 것은 H-SA 이외 에도 M-SA가 뚜렷이 관찰되고 있었다. 이로 보아 산소 공공이 H-SA의 합성에 기여하고 있음을 확인할 수 있었 다. 즉, 산소 공공은 불안정상인 $\mathrm{H}-\mathrm{SA}$ 를 안정화시키는 역 할을 한다고 생각된다. 그러나 산화분위기에서 열처리를 함으로써 산소 공공이 산소로 채워지게 되고, 불안정상 인 H-SA에서 안정상인 M-SA 상으로의 상전이가 일어 나게 된 것이다.

\section{4. 결 론}

$\mathrm{Ca}_{1-\mathrm{x}} \mathrm{Sr}_{\mathrm{x}} \mathrm{Al}_{2} \mathrm{O}_{4}: \mathrm{Eu}^{2+}$ 형광체는 $\mathrm{Sr}$ 의 첨가량에 따라 $\mathrm{M}$ $\mathrm{CA}, \mathrm{H}-\mathrm{SA}$ 그리고 M-SA로 상전이가 발생하였으며 그에
따라 PL 특성도 변하였다. M-CA에서 H-SA로의 상전이 는 환원분위기에서만 발생하였으며, 산화분위기에서는 나 타나지 않았다. 환원분위기 하에서 고온상인 H-SA가 상 온에서도 합성된 것은 산소공공 때문이다. 이는 산화분 위기에서 열처리한 시편의 경우 고온상인 $\mathrm{H}-\mathrm{SA}$ 의 생성 이 억제된 것으로부터 알 수 있었다. $\mathrm{Ca}_{1-\mathrm{x}} \mathrm{Sr}_{\mathrm{x}} \mathrm{Al}_{2} \mathrm{O}_{4}: \mathrm{Eu}^{2+}$ 에서 $\mathrm{Sr}$ 양의 증가에 따른 상전이는 $\mathrm{PL}$ 특성에 영향을 주 었다. M-CA가 주도상인 영역에서는 $450 \mathrm{~nm}$ 근처에서 청 색발광을 하였고 $\mathrm{H}-\mathrm{SA}$ 와 $\mathrm{M}-\mathrm{SA}$ 가 주도상인 영역에서는 $500 \mathrm{~nm}$ 근처에서 녹색발광을 하고 있었다.

\section{감사의 글}

본 연구는 2006학년도 경기대학교 학술연구비(연구그 룹연구과제) 지원에 의하여 수행되었음.

\section{참 고 문 헌}

1. L. T. Chen, C. S. Hwang, I. L. Sun and I. G. Chen, J. Lumin., 118, 12 (2006).

2. T. Aitasalo, J. Hilsa, H. Jungner, M. Lastusaari, J. Niittykoski, M. Paekkinen and R. Valtonen, Opt. Mater., 26, 113 (2004).

3. Z. Fu, S. Zhou, Y. Yu and S. Zang, Chem. Phys. Lett., 395, 285 (2004).

4. T. Aitasalo, J. Hilsa, H. Jungner, M. Lastusaari and J. Niittykoski, J. Alloys Comp., 341, 76 (2002).

5. T. Aitasalo, J. Hilsa, H. Jungner, M. Lastusaari and J. Niittykoski, J. Lumin., 94, 59 (2001).

6. J. Hilsa, H. Jungner, M. Lastusaari and J. Niittykoski, J. Alloys Comp., 323, 326 (2001).

7. Y. Lin, Z. Zhang, Z. Tang, J. Zhang, Z. Zheng and X. Lu, Mater. Chem. Phys., 70, 156 (2001).

8. W. S. Shi, H. Yamada, K. Nishikubo, H. Kusaba and C. N. Xu, J. Electrochem. Soc., 151, H97 (2004).

9. D. Ravichandran, S. T. Johnson, S. Erdei, R. Roy and W. B. White, Display, 19, 197 (1999).

10. L. T. Chen, C. S. Hwang, I. G. Chen and S. J. Chang, J. Alloys Comp., 426, 395 (2006).

11. S. H. Ju, S. G. Kim, J. C. Choi, H. L. Park, S.-I. Mho and T. W. Kim, Mater. Res. Bull., 34, 1905 (1999).

12. T. -P. Tang, C. -M. Lee and F. -C. Yen, Ceram. Int., 32, 665 (2006).

13. C. Chang, D. Mao, J. Shen and C. Feng, J. Alloys Compd., 348, 224 (2003).

14. A.K. Prodjosantoso and B.J. Kennedy, Mater. Res. Bull., 38, 79 (2003).

15. C. Zhu, Y. Yang, G. Chen, S. Baccaro, A. Cecilia and M. Falconieri, J. Phys. Chem. Solids, 68, 1721 (2007).

16. S. Ito, S. Banno, K. Suzuki and M. Inagaki, Z. Phys. Chem., Neuw Folge, 105, 173 (1977).

17. D. D. Jia, B. Q. Wu and J. Zhu, Chin. Phys., 9, 69 (2002). 